\title{
Protective Effect of Processed Panax ginseng, Sun Ginseng on UVB- irradiated Human Skin Keratinocyte and Human Dermal Fibroblast
}

\author{
Hyejin Lee ${ }^{1}$, Joo Yeop Lee ${ }^{1}$, Kyu Choon Song ${ }^{1}$, Jinhee Kim ${ }^{1}$, Jeong Hill Park ${ }^{2}$, Kwang-Hoon Chun ${ }^{3 *}$, \\ and Gwi Seo Hwang ${ }^{*}$
}

${ }^{1}$ Lab of Cell Differentiation Research, College of Oriental Medicine, Gachon University, Seongnam 461-701, Korea

${ }^{2}$ College of Pharmacy, Seoul National University, Seoul 151-742, Korea

${ }^{3}$ College of Pharmacy, Gachon University, Incheon 406-799, Korea

In this study, we investigated the protective effects of processed Panax ginseng, sun ginseng (SG) against the UVB-irradiation on epidermal keratinocytes and dermal fibroblasts. Pretreatment of SG in HaCaT keratinocytes and human dermal fibroblasts reduced UVB-induced cell damage as seen by reduced lactate dehydrogenase release. We also found that SG restored the UVB-induced decrease in anti-apoptotic gene expression (bcl-2 and bcl-xL) in these cells, indicating that SG has an anti-apoptotic effect and thus can protect cells from cell death caused by strong UVB radiation. In addition, SG inhibited the excessive expression of c-jun and c-fos gene by the UVB in HeCaT cells and human dermal fibroblasts. We also demonstrated that SG may exert an anti-inflammatory activity by reducing the nitric oxide production and inducible nitric oxide synthase mRNA synthesis in HaCaT keratinocytes and human dermal fibroblasts. This was further supported by its inhibitory effects on the elevated cyclooxygenase-2 and tumor necrosis factor- $\alpha$ transcription which was induced by UVB-irradiation in $\mathrm{HaCaT}$ cells. In addition, SG may have anti-aging property in terms of induction of procollagen gene expression and inhibition of the matrix metalloprotease-1 gene expression caused by UVBexposure. These findings suggest that SG can be a potential agent that may protect against the dermal cell damage caused by UVB.

Keywords: Panax ginseng, Sun ginseng (SG), Ultraviolet radiation, Keratinocytes, Matrix metalloprotease-1

\section{INTRODUCTION}

UV damage is a major environmental factor causing skin aging and skin cancer. UV light is composed of UVC (200-280 nm), UVB (280-315 nm), and UVA (315$400 \mathrm{~nm})$. UVB is genotoxic for keratinocytes causing DNA damage directly by the formation of cyclobutanepyrimidine dimers and 6-4 pyrimidine-pyrimidone photoproducts [1]. Furthermore, UVB radiation induces DNA damage indirectly by inducing oxidative stress and free radicals, leading to tumor initiation [2]. Meanwhile, high doses of UVB can induce apoptosis, which plays a defensive role to remove severely damaged cells that can be malignant cells [3]. After cancer initiation, cells can enter the stages of tumor promotion and progression of carcinogenesis. Later, two stages are accelerated by inflammation, reactive oxygen species (ROS) generation and uncontrolled proliferation, rendering the cells (c) This is an Open Access article distributed under the terms of the Creative Commons Attribution Non-Commercial License (http://creativecommons.org/licenses/by-nc/3.0/) which permits unrestricted non-commercial use, distribution, and reproduction in any medium, provided the original work is properly cited.
Received 02 Dec. 2011, Revised 29 Dec. 2011, Accepted 29 Dec. 2011

"Corresponding authors

E-mail: seoul@kyungwon.ac.kr

Tel: +82-31-750-5421, Fax: +82-31-721-7029

E-mail:khchun@gachon.ac.kr

Tel: +82-32-899-6117, Fax: +82-32-899-6118 
malignant [4]. In UVB-damaged cells, nuclear factor$\kappa \mathrm{B}(\mathrm{NF}-\kappa \mathrm{B})$ upregulates the levels of inflammation- and proliferation-regulating proteins, such as interleukin (IL)1, tumor necrosis factor (TNF), matrix metalloprotease (MMP)-1, basic fibroblast growth factor, and some components of the AP-1 family in skin fibroblasts and keratinocytes. UVB is also considered to be a major cause of photoaging, which is characterized by skin wrinkling, laxity, roughness, dryness, and pigmentation. These pathological conditions are caused by keratinocyte proliferation and degradation of collagen fibers [5]. With an increased incidence of damaging effects from UVB exposure, novel chemoprevention trials and therapeutic strategies are demanded.

The Panax ginseng Meyer is a widely used traditional herbal medicine having multi-functional activities [6]. Ginseng has been used for its anti-inflammatory, antioxidant [7], anti-tumor promoting [8], and anti-aging [9] activities. Kim et al. [10] reported a new processed ginseng, named as sun ginseng (SG) which was prepared by steaming at high temperature. SG contains different types of ginsenosides such as $\mathrm{Rg}_{3}, \mathrm{Rg}_{5}, \mathrm{Rk}_{1}, \mathrm{Rk}_{2}, \mathrm{Rk}_{3}, \mathrm{Rs}_{4}, \mathrm{Rs}_{5}$, $\mathrm{Rs}_{6}$, and $\mathrm{Rs}_{7}$, which endow SG with more potent pharmacological effects than red ginseng in certain pathological conditions. Various biological activities were reported with SG [11-14], however, the protective effect of SG against UVB-irradiation in skin-related problems has yet to be evaluated.

In this report, to elucidate the protective role of SG against UVB-irradiation, we tested SG's anti-cytotoxic, antioxidant, anti-inflammatory, and anti-aging effects on UVB-irradiated HaCaT human keratinocytes and human dermal fibroblasts.

\section{MATERIALS AND METHODS}

\section{Reagents}

3-(4,5-dimethylthiazol-2-yl)-2,5-diphenyltetrazolium bromide and a lactate dehydrogenase (LDH) assay kit were purchased from Sigma (St. Louis, MO, USA). RNAiso Plus, a Primescript 1st strand cDNA synthesis Kit, and a SYBR Premix Ex Taq real time PCR kit were purchased from Takara Bio Inc. (Shiga, Japan). SG extract powder was provided by Ginseng Science Inc. (Seoul, Korea). The SG extract powder was dissolved in DMSO, passed through filter paper, and added to the cells at the indicated concentration.

\section{Cell culture}

The human keratinocyte cell line, HaCaT (kindly pro- vided by Professor TY Kim from The Catholic University of Korea, Seoul, Korea) was grown at $37^{\circ} \mathrm{C}$ in Dulbecco's modified Eagle's medium (DMEM) (WelGENE, Daegu, Korea) supplemented with 10\% heat-inactivated fetal bovine serum (FBS) (Lonza, Walkersville, MD, USA) and 1\% penicillin/streptomycin (Gibco BRL Life Technology, Grand Island, NY, USA) in a $5 \% \mathrm{CO}_{2}$-air atmosphere. Human dermal fibroblasts purchased from Lonza were maintained in DMEM medium containing $10 \% \mathrm{FBS}$ and $1 \%$ penicillin/streptomycin in a humidified incubator.

\section{UVB irradiation and treatment}

Cells were pretreated with different concentrations of $\mathrm{SG}$ for $1 \mathrm{~h}$ and then replenished with fresh medium. The treated cells were washed with PBS and exposed to a radiation dose of $30 \mathrm{~mJ} / \mathrm{cm}^{2}$ of UVB (290-320 nm) light by a UV meter (UVATEC Inc., Sherman Oaks, CA, USA). After irradiation, the cells were replaced with fresh medium containing different concentrations of SG for $3 \mathrm{~d}$.

\section{Lactate dehydrogenase leakage assay}

To assess the effects of SG on UVB-irradiated HaCaT and dermal fibroblasts, cell viability was measured by a LDH leakage using an assay kit according to the manufacturer's instructions. Cells were treated and incubated as described above. The culture media were used as an indicator of the cell membrane integrity. The enzyme activity was measured at $30^{\circ} \mathrm{C}$ and cell viability is represented as a percentage of control.

\section{Determination of nitric oxide production}

Estimation of nitric oxide (NO) production was performed according to the established protocol [15]. HaCaT and dermal fibroblasts were plated into 96 well-plates and incubated. Following incubation, the cell medium was replaced by a phenol red-free fresh medium containing different concentrations of SG for $1 \mathrm{~h}$ and exposed to UVB. After $3 \mathrm{~d}$, the culture media were transferred into a new plate and mixed with $20 \mu \mathrm{L}$ of Griess reagent. To measure NO production, the mixture was incubated for $20 \mathrm{~min}$ at room temperature and the absorbance was measured at $548 \mathrm{~nm}$ by a microplate reader. The extracellular release of $\mathrm{NO}$ was calculated from a sodium nitrite standard curve.

\section{RNA extraction and quantitative real time poly- merase chain reaction}

Total RNA was isolated by TRIzol reagent (Invitrogen, Carlsbad, CA, USA) according to the manufacturer's 
Table 1. Oligonucleotide primer sequences used in quantitative real time polymerase chain reaction

\begin{tabular}{|c|c|c|}
\hline Gene name & Forward primer & Reverse primer \\
\hline iNOS & CGGTGCTGTATTTCCTTACGAGGCGAAGAAGG & GGTGCTGTCTGTTAGGAGGTCCAAGTAAAGGGC \\
\hline bcl-2 & ACTCTGCTCAGTTTCGCCCT & TTGTGGCTCAGATAGGCAC \\
\hline bcl-xL & ATGTCTCAGAGCAACCGG & TCTTTCCGACTGAAGAGTG \\
\hline$c-j u n$ & GGATCAAGGCGGAGAGGAAG & GCGTTAGCATGAGTTGGCAC \\
\hline$c-f o s$ & GGAGAATCCGAAGGAAAGG & GCTTGGGCTCAGGGTCATTG \\
\hline TNF- $\alpha$ & TGCACCACAGTTTAAACCCA & GACTCCTTCAGGTGCTCAGG \\
\hline Procollagen I $\alpha 2$ & GTGGTTACTACTGGATTGACC & TTGCCAGTCTCCTCATCCAT \\
\hline MMP-1 & CGACTCTAGAAACACAAGAGCAAGA & AAGGTTAGCTTACTGTCACACGCTT \\
\hline GAPDH & CAGCCTCGTCCCGTAGACAAA & CACGACATACTCAGCACCGGC \\
\hline
\end{tabular}

iNOS, inducible nitric oxide synthase; TNF, tumor necrosis factor; MMP, matrix metalloprotease; GAPDH, glyceraldehyde-3-phosphate dehydrogenase.

instructions. RNA concentrations and purity were determined using NonoDrop ND-1000 (NanoDrop Technologies Inc., Rockland DE, USA). Total RNA was synthesized to first strand cDNA using a PrimeScript 1st strand cDNA synthsis Kit. The cDNA was amplified to estimate the gene expression level by quantitative real time polymerase chain reaction (PCR). PCR reactions were performed using a SYBR premix Ex Taqkit and conducted using a Takara dice real time system. All mRNA levels were normalized using the GAPDH mRNA level as an internal control. The primers used in amplification are shown in Table 1.

\section{Statistical analysis}

The experiments were carried out three times for each sample. Data were expressed as mean $\pm \mathrm{SD}(n=3)$. Statistical analyses were performed using a Student's $t$-test. Differences were considered significant at ${ }^{* *} p<0.01$. vs. normal control and ${ }^{\#} p<0.05, \stackrel{\#}{\#}<<0.01$. vs. UV irradiated cell control (UVB).

\section{RESULTS}

\section{Sun ginseng has a protective effect against UVB- induced cell damage}

UVB exposure causes DNA damage by producing pyrimidine dimers, eventually leading to cell death in human epidermal cells [16]. To determine the preventive effect of SG on cell damage, we measured LDH levels in UVB-irradiated $\mathrm{HaCaT}$ cells with or without $\mathrm{SG}$ pretreatment for 3 d. As shown in Fig. 1A, UVB-irradiation increased LDH release markedly by $80 \%$ in $\mathrm{HaCaT}$ cells. SG pretreatment inhibited UVB-induced LDH release in a dose-dependent manner, up to $27.8 \%$ at $50 \mu \mathrm{g} / \mathrm{mL}$ as compared to the UVB-irradiated control. When this assay was performed under the same conditions for human dermal fibroblasts, similar results were obtained, with a $32.4 \%$ decrease at 50 $\mu \mathrm{g} / \mathrm{mL}$ pretreatment of SG (Fig. 1B).
UV irradiation induces apoptosis by down-regulation of the bcl-2 family, anti-apoptotic regulators, in the human epidermis [17]. Overexpression of bcl-2 or bcl-xL prevents cells from apoptosis induced by various stimuli including UV radiation [18-20]. To examine the effect of SG on UV-induced apoptosis, we exposed UV-irradiation on keratinocytes and fibroblasts with or without pre-treatment of SG for $3 \mathrm{~d}$ and observed bcl-2 and bclxL mRNA levels by a real-time PCR analysis. By UVB exposure, the anti-apoptotic bcl-2 mRNA was reduced by $80 \%$ in $\mathrm{HaCaT}$ cells, as expected (Fig. 1C). Ten $\mu \mathrm{g} /$ $\mathrm{mL}$ of SG pre-treatment restored bcl-2 mRNA expression by $37.5 \%$ compared to the UVB-irradiated control, whereas $50 \mu \mathrm{g} / \mathrm{mL}$ of SG pre-treatment restored the bcl2 mRNA level almost to the non UVB-exposured control (NC) level (Fig. 1C). We further tested whether the mRNA level of bcl-xL, another bcl-2 family member was also restored by $\mathrm{SG}$ pre-treatment in $\mathrm{HaCaT}$ cells (Fig. 1D). In the dermal fibroblast, the anti-apoptotic bcl-2 mRNA level was reduced by 55\% after UVBexposure compared with the normal control (Fig. 1E). Under the same conditions as above, SG (10 and $50 \mu \mathrm{g} /$ $\mathrm{mL}$ ) dramatically increased bcl-2 expression by $66.7 \%$ and $133 \%$, respectively, compared to UVB-irradiated control (Fig. 1E). UVB irradiation also decreased the bcl-xL mRNA level, and this down-regulation was efficiently relieved by $50 \mu \mathrm{g} / \mathrm{mL}$ of SG pre-treatment up to $125 \%$ as compared with the UVB-irradiated control in fibroblast (Fig. 1F). Consistent with the results for $\mathrm{HaCaT}$ cells, UVB irradiation significantly decreased the bcl-xL mRNA level in dermal fibroblasts. As shown in Fig. 1F, 2, 10 and $50 \mu \mathrm{g} / \mathrm{mL}$ SG pre-incubation showed $37.5,50$ and $125 \%$ increases as compared to the UVB-irradiated control in the dermal fibroblasts. Altogether, these data indicate that SG is a highly effective in the prevention of UVB-induced damage and cell death in keratinocytes and fibroblasts. 
A. HaCaT: LDH assay

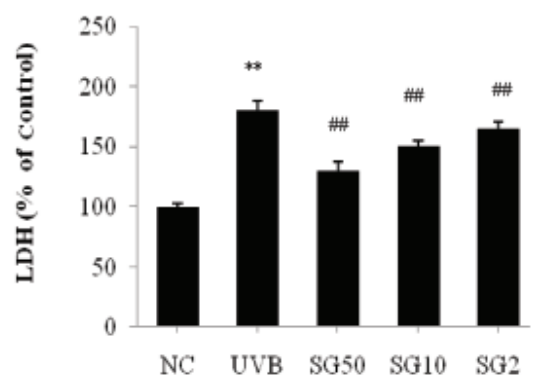

C. HaCaT: bcl-2 expression

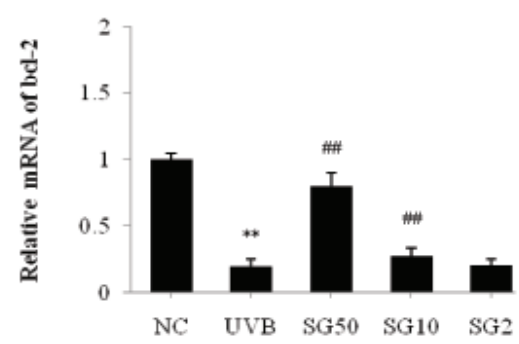

E . Dermal fibroblast: bcl-2 expression

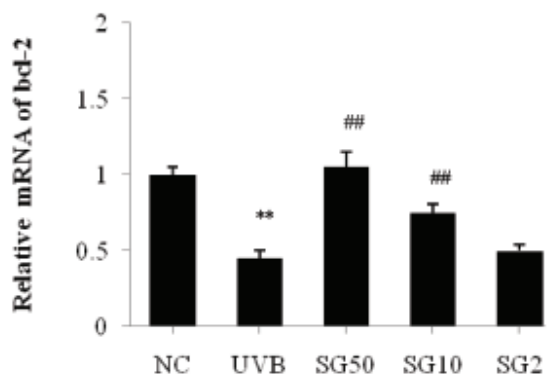

B. Dermal fibroblast: LDH assay

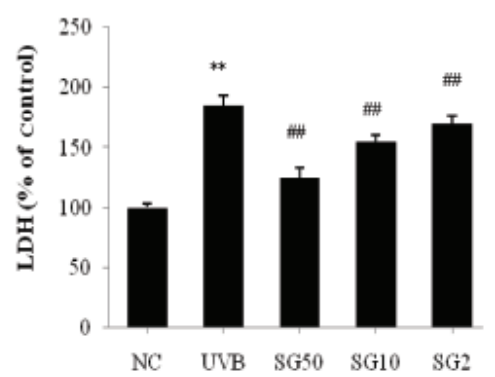

D. HaCaT: bcl-xL expression

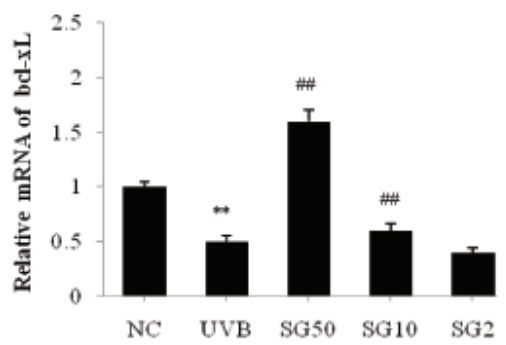

F. Dermal fibroblast: bcl-xL expression

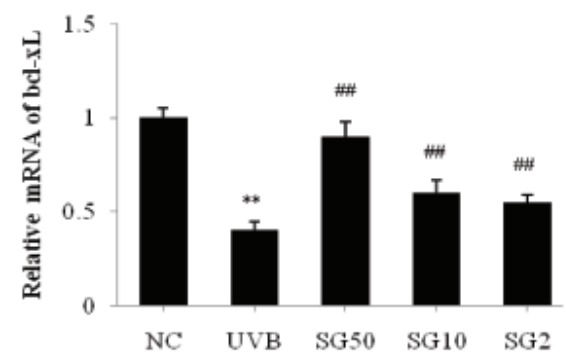

Fig. 1. Protective effects of sun ginseng (SG) against UVB-irradiation. After treatment and irradiation, an lactate dehydrogenase (LDH) leakage assay was performed to determine the cell viability. LDH leakage was expressed as a percentage of the control in HaCaT cells (A) and dermal fibroblasts (B). Real time-polymerase chain reaction of bcl-2 and bcl-xL was performed in $\mathrm{HaCaT}$ cells $(\mathrm{C}, \mathrm{D})$ and fibroblasts (E,F) to analyze the effects of SG on gene expression of anti-apoptotic genes. Cells were pretreated with the indicated concentration of SG and exposed to UVB. Data represent the mean \pm SD of triplicate experiments. NC, normal control; UVB, UVB irradiated control; SG 50 , SG 10 and SG 2, pretreated cells with 50,10 and $2 \mu \mathrm{g} / \mathrm{mL}$ of SG before UVB exposure. Differences were considered significant at " $p<0.01 \mathrm{vs}$. NC and ${ }^{\# \#} p<0.01 \mathrm{vs}$. UVB.

\section{Sun ginseng decreased c-jun and c-fos expression in UVB-irradiated keratinocytes and fibroblasts}

Irradiation of HaCaT cells with UVB induces gene expression of $c$-fos, a member of the AP-1 protein family of transcription factors [21]. In order to assess the role of SG in the regulation of $c$-jun and c-fos expressions, mRNA levels were measured by a real-time PCR analy- sis in UVB-irradiated $\mathrm{HaCaT}$ cells with or without SG pre-incubation. As shown in Fig. 2A, UVB significantly increased the $c$-jun mRNA level; in contrast, SG pretreatment $(10,50 \mu \mathrm{g} / \mathrm{mL})$ decreased the $c$-jun mRNA by 26.5 and $53 \%$, respectively, as compared to the UVBirradiated control. Also, UVB exposure increased $c$-fos mRNA significantly and SG pre-treatment $(2,10,50 \mu \mathrm{g} /$ 
A

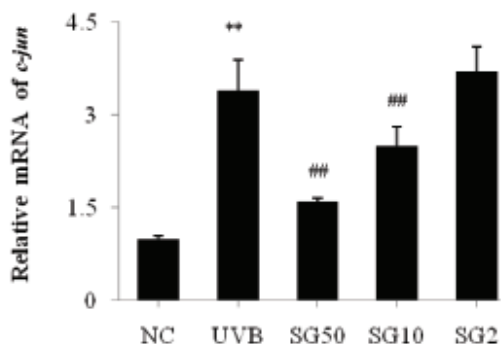

C.

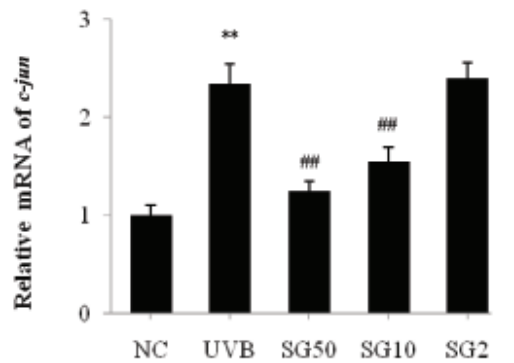

B. HaCaT: $c$-fos expression

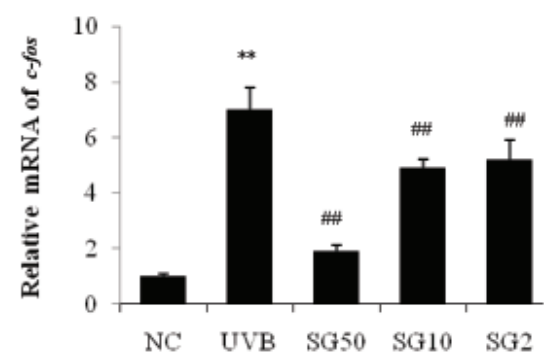

D. Dermal fibroblast: $c$-fos expression

Fig. 2. Effects of sun ginseng (SG) on gene expression of $c$-jun and $c$-fos in UVB-irradiated HaCaT cells $(A, B)$ and dermal fibroblasts (C,D). To analyze the effects of SG $c$-jun and $c$-fos gene expression by a real time- polymerase chain reaction analysis, cells were pretreated with the indicated concentration of SG and exposed to UVB. Data represent the mean $\pm S D$ of triplicate experiments. NC, normal control; UVB, UVB irradiated control; SG 50, SG 10 and SG 2, pretreated cells with 50, 10 and $2 \mu \mathrm{g} / \mathrm{mL}$ of SG before UVB exposure. Differences were considered significant at ${ }^{* *} p<0.01$ vs. NC and ${ }^{\# \#} p<0.01$ vs. UVB.

$\mathrm{mL}$ ) showed $25.7,30$, and $72.9 \%$ decreases as compared to the UVB-irradiated control (Fig. 2B). In the dermal fibroblasts, we observed a similar pattern: the increased $c$ jun mRNA level by UVB-exposure was reduced by $34 \%$ and $46.7 \%$ with 10 and $50 \mu \mathrm{g} / \mathrm{mL}$ of SG pre-treatment, respectively, as compared to the UVB-irradiated control (Fig. 2C). c-fos mRNA expression was significantly increased by UVB-irradiation, but reduced by SG pretreatment dose-dependently, showing a $73.3 \%$ decrease at $50 \mu \mathrm{g} / \mathrm{mL}$ of SG, as compared to the UVB-irradiated control (Fig. 2D).

\section{Sun ginseng has potent anti-oxidative and anti- inflammatory effects on UVB-irradiated keratino- cytes and fibroblasts}

UVB exposure stimulates production of the proinflammatory cytokines such as interferon (IFN)gamma, IL-6, and TNF- $\alpha$, and prostaglandins which are implicated in progress of carcinogenesis [22]. These cytokines, as well as oxidative stress, stimulate gene expressions of inducible nitric oxide synthase (iNOS) and cyclooxygenase (COX)-2 via NF-kB activation resulting in NO synthesis and inflammation. To examine SG's effect on UVB-induced inflammation, we measured NO production using Griess reagent. Stimulation with UVBexposure increased NO production by $48 \%$ in $\mathrm{HaCaT}$ cells. SG was observed to dose-dependently decrease NO production up to $30 \%$ as compared to the UVB-irradiated control (Fig. 3A). In dermal fibroblasts, 2, 10, and $50 \mu \mathrm{g} /$ $\mathrm{mL}$ of SG was observed to dose-dependently decrease NO production by $11.4,32.9$, and $37.1 \%$ as compared to the UVB-irradiated control (Fig. 3B). We further tested whether SG can prevent UVB-induced gene expression of pro-inflammatory molecules by a real-time PCR analysis. Results demonstrated that pre-treatment of SG led to a significant decrease in UVB-induced inflammatory gene levels. Pretreatment of 2, 10, and $50 \mu \mathrm{g} / \mathrm{mL}$ of SG pre-treatment significantly downregulated UVB- 
A. HaCaT: NO production

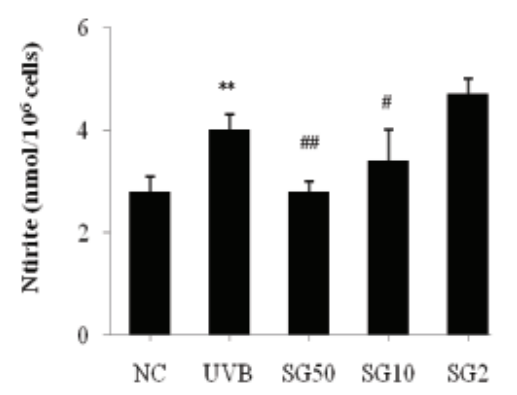

C. HaCaT: iNOS expression

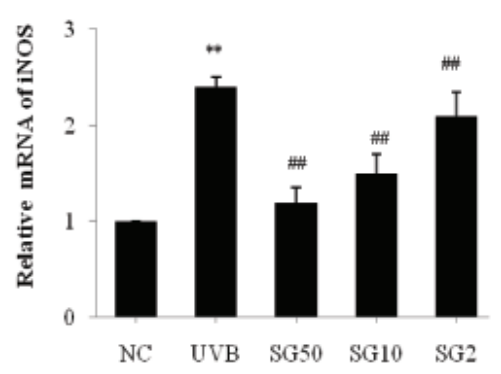

E. HaCaT: TNF- $\alpha$ expression

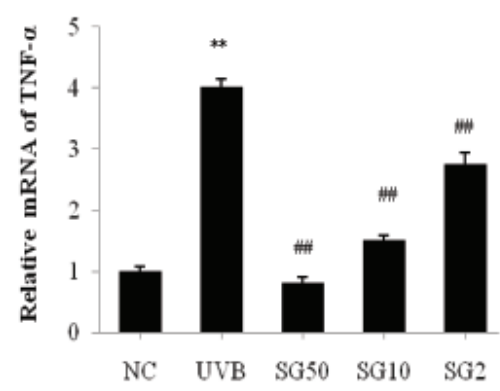

B. Dermal fibroblast: NO production

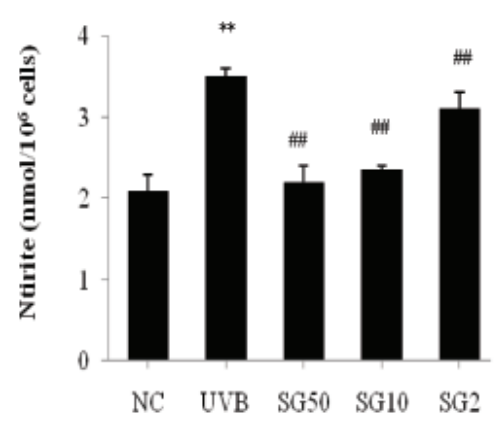

D. Dermal fibrolbast: iNOS expression

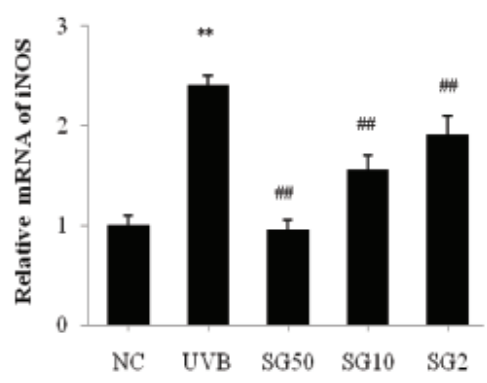

F. HaCaT: COX-2 expression

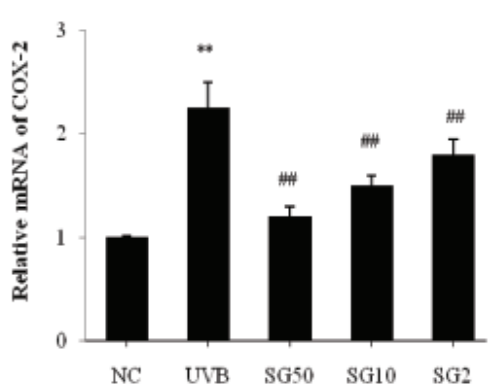

Fig. 3. Anti-oxidative and anti-inflammatory effects of sun ginseng (SG). Nitric oxide (NO) production was accessed with conditioned media using Griess reagents in HaCaT cells (A) and dermal fibroblasts (B). The extracellular release of NO was calculated from a sodium nitrite standard curve. To analyze the inducible nitric oxide synthase (iNOS) (C. in HaCaT and D. in fibroblasts), tumor necrosis factor (TNF)- $\alpha$ (E. in HaCaT) and cyclooxygenase (COX)-2 ( $\mathrm{F}$. in HaCaT) gene expression by a real time-polymerase chain reaction analysis, cells were pretreated with the indicated concentration of SG and exposed to UVB. Data represent the mean $\pm S D$ of triplicate experiments. NC, normal control; UVB, UVB irradiated control; SG 50, SG 10 and SG 2, pretreated cells with 50,10 and $2 \mu \mathrm{g} / \mathrm{mL}$ of SG before UVB exposure. Differences were considered significant at $" p<0.01$ vs. NC and ${ }^{\#} p<0.05,{ }^{* \#} p<0.01$ vs. UVB.

induced iNOS mRNA synthesis by $12.5,37.5$, and $50 \%$ as compared to UVB-irradiated HaCaT cells (Fig. 3C). In dermal fibroblasts, UVB induced a $140 \%$ increase of the iNOS mRNA level as compared to NC and SG dosedependently $(2,10$ and $50 \mu \mathrm{g} / \mathrm{mL})$ caused $20.8,35.4$, and $60.4 \%$ reductions of iNOS expression (Fig. 3D).
Pretreatment of 2, 10, and $50 \mu \mathrm{g} / \mathrm{mL}$ of SG was observed to decrease TNF- $\alpha$ mRNA levels by $31.3,62.5$, and $80 \%$ (Fig. 3D), and also COX-2 mRNA synthesis by 20, 33.3, and $46.7 \%$ (Fig. $3 \mathrm{~F}$ ), respectively, as compared to UVBirradiated $\mathrm{HaCaT}$ cells. 
A. Dermal fibroblast: procollagen I expression

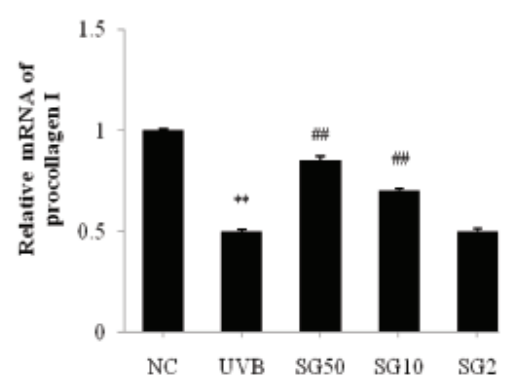

B. Dermal fibroblast: MMP-1 expression

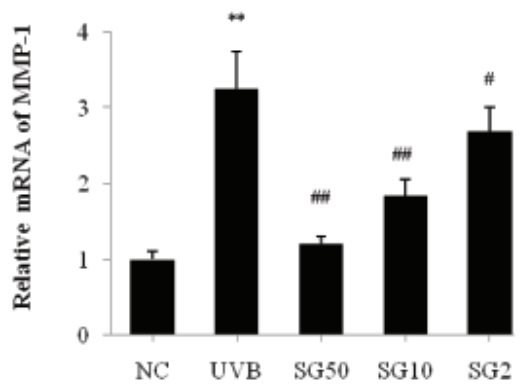

Fig. 4. Effects of sun ginseng (SG) on the procollagen and matrix metalloprotease (MMP)-1 gene expression in UVB-irradiated dermal fibroblasts. To analyze the effects of SG on the gene expression of procollagen (A) and MMP-1 (B) by a real time-polymerase chain reaction analysis, fibroblasts were pretreated with the indicated concentration of $S G$ and exposed to UVB. Data represent the mean $\pm S D$ of triplicate experiments. NC, normal control; UVB, UVB irradiated control; SG 50, SG 10 and SG 2, pretreated cells with 50,10 and $2 \mu \mathrm{g} / \mathrm{mL}$ of SG before UVB exposure. Differences were considered significant at " $p<0.01$ vs. NC and ${ }^{\#} p<0.05,{ }^{\#} p<0.01$ vs. UVB.

\section{Sun ginseng increased procollagen gene expres- sion by decreasing matrix metalloprotease-1 ex- pression in UVB-irradiated dermal fibroblasts}

Dermal fibroblasts were pretreated with the indicated concentration of SG and then exposed to UVB for $3 \mathrm{~d}$. As shown in Fig. 4A, UVB significantly decreased the procollagen mRNA level by $50 \%$ as compared to the normal control and SG dose-dependently (10 and 50 $\mu \mathrm{g} / \mathrm{mL}$ ) caused $40 \%$ and $70 \%$ recovery of procollagen expression. The degradation of procollagen is mediated by MMPs, which are zinc-dependent proteases secreted from fibroblasts. We further investigated whether SG affects the MMP-1 activation by UVB through an evaluation of the MMP-1 mRNA level by a real time PCR analysis. Consistent with other studies [23,24], UVB significantly increased the MMP-1 mRNA level, and 2, 10 , and $50 \mu \mathrm{g} / \mathrm{mL}$ of SG dose-dependently decreased the MMP-1 gene expression by $16.9,43$, and $63.1 \%$, respectively as compared to the UVB-irradiated control (Fig. 4B). These data suggest that SG could protect the loss of collagen in human dermal fibroblast induced by UVB exposure.

\section{DISCUSSION}

Although ginseng has been used as an effective agent with protective and curable roles in a variety of diseases, processed ginseng, SG has not been studied for its protective role against UVB-induced damage. We examined the effects of SG on the regulation of gene expressions of the key molecules involved in UVB-induced cell damage in human skin keratinocyte and human dermal fibroblast.
Our data from a LDH leakage assay and measurement of apoptosis in two different cell lines show that SG has a protective role against UVB-induced cell damage, suggesting some potential activity in facilitating skin dermis regeneration (Fig. 1A).

Our study also demonstrates that SG protects against UVB-induced apoptosis in keratinocytes and fibroblasts by showing that downregulated mRNA levels of bcl-2 and bcl-xL from UVB irradiation were restored by SG treatment. Overexpression of anti-apoptotic factors, bcl2 or bcl-xL, prevents apoptosis of cells induced by various stimuli including UV radiation [17-19]. Rieber and Rieber [20] reported that N-acetylserine enhances UVinduced apoptosis by inhibiting ectopic bcl-2 expression. Also, baicalin protects mouse epidermis against UVB irradiation by up-regulating bcl-2 expression [25]. This protective role against UVB-irradiation was also reported other naturally occurring agents. Ginseng components decrease UVB-induced cell damage by increasing DNA repair and decreasing apoptosis in human skin [26,27]. In addition, inositol hexaphosphate (IP6) protects UVBexposed cells from apoptosis by cell cycle arrest in the G1 and G2/M phases and by inactivation of caspase-3 [28]. Also, some reports showed that IP6 protects mice from UVB-induced tumors [29]. Pomegranate (form Punica granatum) or sesamol (from Sesamum indicum) exert regeneration against UVB-induced cell damage in fibroblasts [30,31].

Although high dose UV-exposure induces apoptosis to prevent the regeneration of DNA-mutated cells, UVB also induces cell proliferation directly/indirectly by increasing AP-1 activity in human dermal fibroblasts 
[32,33] and human keratinocytes [34,35], which may be responsible for the malignancy of DNA-damaged cells. The AP-1 family includes c-myc, $c$-jun, and $c-f o s$ that form intracellular complexes associated with transcriptional control elements such as AP-1 sites. It is reported that $c-j u n$ and $c$-fos are predominant molecules of transcription factors mediating gene expression induced by UVB irradiation. Several studies have shown that UVB induces $c$-jun and $c$-fos expression in keratinocyte cell line as well as in dermal fibroblasts [21,32]. Glycolic acid derived from fruit and mild sugars, has an inhibitory effect against UVB-induced AP-1 activation in HaCaT cells [36].

UVB exposure induces a release of free radicals such as $\mathrm{NO}$ and superoxide $\left(\mathrm{O}_{2}{ }^{-}\right)$in human keratinocytes. $\mathrm{NO}$ is synthesized by NOS from L-arginine and reacts with $\mathrm{O}_{2}{ }^{-}$to produce peroxynitrite $\left(\mathrm{ONOO}^{-}\right)$, which accelerates apoptosis by potent oxidative efficacy. Skin keratinocytes comprising $90 \%$ to $95 \%$ of cells in the epidermis induce iNOS expression after UV irradiation $[37,38]$ and iNOS may play a role in NO production in the late phase postUVB. Previous studies have shown that NO production and iNOS gene expression are affected in UV-exposed fibroblasts $[39,40]$. Lu et al. [40] reported that NO production and iNOS expression are increased dose-dependently by UV-exposure and iNOS-mediated oxidative stress plays a role in the regulation of eIF2 alpha phosphorylation, leading to apoptosis upon UV irradiation in human primary cutaneous fibroblasts.

Korean red ginseng extract has been reported to protect cells against $\mathrm{ONOO}^{-}$induced genotoxicity through modulation of p53 [41]. SG, heat-processed ginseng, was reported to have increased free radical scavenging activity as compared to dried- or steamed raw ginseng. SG showed $\mathrm{NO}, \mathrm{O}_{2}^{-}$, hydroxyl radical, and $\mathrm{ONOO}^{-}$scavenging activities [42]. Our data imply that SG exerts an antiapoptotic effect, possibly by reducing NO production through suppression of iNOS mRNA transcription.

UVB-irradiated keratinocytes produce intracellular ROS or reactive nitrogen species, inducing inflammation, apoptosis or aging, and secretion of cytokines (transforming growth factor- $\beta$, TNF- $\alpha$, prostaglandin $\mathrm{E}_{2}$, $\alpha$-melanocyte stimulating hormone, granulocyte stimulating factor, IL-1, -6, -8, and-10), stimulating fibroblasts, and melanocyte. UVB exposure also stimulates the production of prostaglandins resulting in induction of inflammation, all of which are implicated in progress of carcinogenesis [22]. Prostaglandins are formed from arachidonic acid by several steps involved with COX-1 and -2 . COX -2 is a primarily upregulated gene in response to UVB exposure in human skin [43], and it is thought that TNF- $\alpha$ may be the major intermediate regulator that transduces UVB-involved signals between keratinocytes and fibroblasts. Our results implicate that SG could repair UVB-induced cell damage through an anti-inflammatory effect due to the inhibition of TNF- $\alpha$ and COX-2 gene expression in keratinocytes, affecting subsequent events in fibroblasts.

Keratinocyte-fibroblast interactions are important in skin protection against UVB irradiation. Exposure to UV damages epidermal and dermal components of human skin [44]. Collagens are extracellular matrix fibrillar molecules and prominent proteins in the dermis that facilitate elasticity, tightening, cell integrity, and other functions. Interstitial collagens are synthesized and secreted as procollagens. Procollagens are cleaved and form collagen peptides followed by completion of synthesis of collagen fibers. Dermal fibroblasts produce collagen by the expression of procollagen, fibrillin-1, and tropoelastin and inhibition of MMPs through keratinocyte-fibroblast interactions. UVB irradiation induces pro-inflammatory cytokines such as IL- $1 \beta$, TNF- $\alpha$, IL- 6 , and IL- 8 in keratinocytes and fibroblasts. These cytokines upregulate MMP production in fibroblasts in two ways. First, UVB exposure can produce IL-6, inducing MMP expression in fibroblasts in an autocrine manner. Second, UVBexposed keratinocytes secrete cytokines, which increase MMP-1 production in fibroblasts. In addition, IL- $1 \alpha$ produced from UV-exposed keratinocytes may indirectly play a role in MMP-1 production in fibroblasts. ECM degradation mediated by MMPs leads to skin fragility, laxity, roughness, dryness, pigmentation, and wrinkle formation. IL-1 and TNF- $\alpha$ secreted from keratinocytes accelerate collagen degradation by inhibiting the expression of procollagen or by activating MMPs in fibroblasts. Some natural products have been reported to reduce the UVB-induced collagen degradation. Glycosidic spinasterol recovered procollagen level in the UVB exposed human dermal fibroblasts [45]. Compounds such as spinasterol might be potentially used as an agent for the protection and treatment of UV-induced skin damage. Lee et al. [46] reported that cordycepin inhibits MMP1 and -3 gene expression and suggested cordycepin as a potent inhibitor of MMPs in post-UVB human dermal fibroblasts. Also, Radix clematidis extract is known as an inhibitor of MMP expression by suppressing NF- $\mathrm{KB}$ in dermal fibroblasts [47]. Our data implicate that SG could increase procollagen production directly and/or indirectly by suppressing MMP-1 gene expression and thus reducing MMP-1 production in fibroblasts, which can be in- 
volved in reduced TNF- $\alpha$ secretion by keratinocytes.

In this study, we suggest that SG has potential anticytotoxic, antioxidant, anti-inflammatory, and anti-aging effects in UVB-irradiated HaCaT human keratinocytes and human dermal fibroblasts.

\section{ACKNOWLEDGEMENTS}

This study was supported by Gachon University Research Fund.

\section{REFERENCES}

1. Kinley JS, Brunborg G, Moan J, Young AR. Detection of UVR-induced DNA damage in mouse epidermis in vivo using alkaline elution. Photochem Photobiol 1995;61:149158.

2. De Gruijl FR. Photocarcinogenesis: UVA vs. UVB radiation. Skin Pharmacol Appl Skin Physiol 2002;15:316320.

3. Kulms D, Schwarz T. Molecular mechanisms of UVinduced apoptosis. Photodermatol Photoimmunol Photomed 2000;16:195-201.

4. Rogers CJ, Colbert LH, Greiner JW, Perkins SN, Hursting SD. Physical activity and cancer prevention: pathways and targets for intervention. Sports Med 2008;38:271296.

5. Bae JY, Choi JS, Kang SW, Lee YJ, Park J, Kang YH. Dietary compound ellagic acid alleviates skin wrinkle and inflammation induced by UV-B irradiation. Exp Dermatol 2010;19:e182-e190.

6. Kiefer D, Pantuso T. Panax ginseng. Am Fam Physician 2003;68:1539-1542.

7. Yun BS, Lee MR, Oh CJ, Cho JH, Wang CY, Gu LJ, Mo EK, Sung CK. Characterization of black ginseng extract with acetyl- and butyrylcholin-esterase inhibitory and antioxidant activities. J Ginseng Res 2010;34:348-354.

8. Yoo DS, Rho HS, Lee YG, Yeom MH, Kim DH, Lee SJ, Hong SY, Lee JH, Cho JY. Ginsenoside F1 modulates cellular responses of skin melanoma cells. J Ginseng Res 2011;35:86-91.

9. Choi KT. Botanical characteristics, pharmacological effects and medicinal components of Korean Panax ginseng C A Meyer. Acta Pharmacol Sin 2008;29:1109-1118.

10. Kim WY, Kim JM, Han SB, Lee SK, Kim ND, Park MK, Kim CK, Park JH. Steaming of ginseng at high temperature enhances biological activity. J Nat Prod 2000;63:1702-1704.

11. Park IH, Piao LZ, Kwon SW, Lee YJ, Cho SY, Park MK, Park JH. Cytotoxic dammarane glycosides from pro- cessed ginseng. Chem Pharm Bull (Tokyo) 2002;50:538540.

12. Baek SH, Piao XL, Lee UJ, Kim HY, Park JH. Reduction of Cisplatin-induced nephrotoxicity by ginsenosides isolated from processed ginseng in cultured renal tubular cells. Biol Pharm Bull 2006;29:2051-2055.

13. Lee JG, Lee YY, Kim SY, Pyo JS, Yun-Choi HS, Park JH. Platelet antiaggregating activity of ginsenosides isolated from processed ginseng. Pharmazie 2009;64:602-604.

14. Kang KS, Yamabe N, Kim HY, Park JH, Yokozawa T. Effects of heat-processed ginseng and its active component ginsenoside $20(\mathrm{~S})-\mathrm{Rg}_{3}$ on the progression of renal damage and dysfunction in type 2 diabetic Otsuka Long-Evans Tokushima Fatty rats. Biol Pharm Bull 2010;33:10771081.

15. Nakai K, Fujii S, Yamamoto A, Igarashi J, Kubota Y, Kosaka H. Effects of high glucose on NO synthesis in human keratinocyte cell line (HaCaT). J Dermatol Sci 2003;31:211-218.

16. Ichihashi M, Ueda M, Budiyanto A, Bito T, Oka M, Fukunaga $\mathrm{M}$, Tsuru $\mathrm{K}$, Horikawa T. UV-induced skin damage. Toxicology 2003;189:21-39.

17. Isoherranen K, Sauroja I, Jansen C, Punnonen K. UV irradiation induces downregulation of bcl-2 expression in vitro and in vivo. Arch Dermatol Res 1999;291:212-216.

18. Kanda N, Watanabe S. 17beta-estradiol inhibits oxidative stress-induced apoptosis in keratinocytes by promoting Bcl-2 expression. J Invest Dermatol 2003;121:1500-1509.

19. Ibrado AM, Huang Y, Fang G, Bhalla K. Bcl-xL overexpression inhibits taxol-induced Yama protease activity and apoptosis. Cell Growth Differ 1996;7:1087-1094.

20. Rieber M, Rieber MS. N-Acetylcysteine enhances UVmediated caspase-3 activation, fragmentation of E2F4, and apoptosis in human C8161 melanoma: inhibition by ectopic Bcl-2 expression. Biochem Pharmacol 2003;65:1593-1601.

21. Chen W, Borchers AH, Dong Z, Powell MB, Bowden GT. UVB irradiation-induced activator protein-1 activation correlates with increased $c$-fos gene expression in a human keratinocyte cell line. J Biol Chem 1998;273:3217632181.

22. Brouxhon S, Konger RL, VanBuskirk J, Sheu TJ, Ryan J, Erdle B, Almudevar A, Breyer RM, Scott G, Pentland AP. Deletion of prostaglandin E2 EP2 receptor protects against ultraviolet-induced carcinogenesis, but increases tumor aggressiveness. J Invest Dermatol 2007;127:439-446.

23. Brenneisen P, Sies H, Scharffetter-Kochanek K. Ultraviolet-B irradiation and matrix metalloproteinases: from induction via signaling to initial events. Ann N Y Acad Sci 2002;973:31-43. 
24. Rittie L, Fisher GJ. UV-light-induced signal cascades and skin aging. Ageing Res Rev 2002;1:705-720.

25. Bing-Rong Z, Song-Liang J, Xiao-E C, Xiang-Fei L, BaoXiang C, Jie G, Dan L. Protective effect of the Baicalin against DNA damage induced by ultraviolet B irradiation to mouse epidermis. Photodermatol Photoimmunol Photomed 2008;24:175-182.

26. Cai BX, Luo D, Lin XF, Gao J. Compound K suppresses ultraviolet radiation-induced apoptosis by inducing DNA repair in human keratinocytes. Arch Pharm Res 2008;31:1483-1488.

27. Jeong SJ, Han SH, Kim DY, Lee JC, Kim HS, Kim BH, Lee JS, Hwang EH, Park JK. Effects of $\mathrm{mRg}_{2}$, a mixture of ginsenosides containing $60 \% \mathrm{Rg}_{2}$, on the ultraviolet Binduced DNA repair synthesis and apoptosis in NIH3T3 cells. Int J Toxicol 2007;26:151-158.

28. Williams KA, Kolappaswamy K, Detolla LJ, Vucenik I. Protective effect of inositol hexaphosphate against UVB damage in HaCaT cells and skin carcinogenesis in SKH1 hairless mice. Comp Med 2011;61:39-44.

29. Kolappaswamy K, Williams KA, Benazzi C, Sarli G, McLeod CG Jr, Vucenik I, DeTolla LJ. Effect of inositol hexaphosphate on the development of UVB-induced skin tumors in SKH1 hairless mice. Comp Med 2009;59:147-152.

30. Pacheco-Palencia LA, Noratto G, Hingorani L, Talcott ST, Mertens-Talcott SU. Protective effects of standardized pomegranate (Punica granatum L.) polyphenolic extract in ultraviolet-irradiated human skin fibroblasts. J Agric Food Chem 2008;56:8434-8441.

31. Ramachandran S, Rajendra Prasad N, Karthikeyan S. Sesamol inhibits UVB-induced ROS generation and subsequent oxidative damage in cultured human skin dermal fibroblasts. Arch Dermatol Res 2010;302:733-744.

32. Soriani M, Hejmadi V, Tyrrell RM. Modulation of $c-j u n$ and $c$-fos transcription by UVB and UVA radiations in human dermal fibroblasts and KB cells. Photochem Photobiol 2000;71:551-558.

33. Isoherranen K, Westermarck J, Kahari VM, Jansen C, Punnonen K. Differential regulation of the AP-1 family members by UV irradiation in vitro and in vivo. Cell Signal 1998;10:191-195.

34. Chen W, Dong Z, Valcic S, Timmermann BN, Bowden GT. Inhibition of ultraviolet B: induced $c$-fos gene expression and p38 mitogen-activated protein kinase activation by (-)-epigallocatechin gallate in a human keratinocyte cell line. Mol Carcinog 1999;24:79-84.

35. Garmyn M, Degreef H. Suppression of UVB-induced $c$ fos and c-jun expression in human keratinocytes by Nacetylcysteine. J Photochem Photobiol B 1997;37:125130.
36. Ahn KS, Park KS, Jung KM, Jung HK, Lee SH, Chung SY, Yang KH, Yun YP, Pyo HB, Park YK et al. Inhibitory effect of glycolic acid on ultraviolet B-induced $c$-fos expression, AP-1 activation and p53-p21 response in a human keratinocyte cell line. Cancer Lett 2002;186:125135.

37. Liu W, Wu S. Differential roles of nitric oxide synthases in regulation of ultraviolet B light-induced apoptosis. Nitric Oxide 2010;23:199-205.

38. Chang HR, Tsao DA, Wang SR, Yu HS. Expression of nitric oxide synthases in keratinocytes after UVB irradiation. Arch Dermatol Res 2003;295:293-296.

39. Chen M, Zhang G, Yi M, Chen X, Li J, Xie H, Chen X. Effect of UVA irradiation on proliferation and NO/iNOS system of human skin fibroblast. Zhong Nan Da Xue Xue Bao Yi Xue Ban 2009;34:705-711.

40. Lu W, Laszlo CF, Miao Z, Chen H, Wu S. The role of nitric-oxide synthase in the regulation of UVB light-induced phosphorylation of the alpha subunit of eukaryotic initiation factor 2. J Biol Chem 2009;284:24281-24288.

41. Kim HD, Ha SE, Kang JR, Park JK. Effect of Korean red ginseng extract on cell death responses in peroxynitritetreated keratinocytes. J Ginseng Res 2010;34:205-211.

42. Kang KS, Kim HY, Pyo JS, Yokozawa T. Increase in the free radical scavenging activity of ginseng by heatprocessing. Biol Pharm Bull 2006;29:750-754.

43. Hong CE, Lyu SY. Anti-inflammatory and anti-oxidative effects of Korean red ginseng extract in human keratinocytes. Immune Netw 2011;11:42-49.

44. Tarozzi A, Marchesi A, Hrelia S, Angeloni C, Andrisano V, Fiori J, Cantelli-Forti G, Hrelia P. Protective effects of cyanidin-3-O-beta-glucopyranoside against UVA-induced oxidative stress in human keratinocytes. Photochem Photobiol 2005;81:623-629.

45. Lee TH, Lee SM, Lee DY, Son Y, Chung DK, Baek NI, Kim J. A glycosidic spinasterol from Koreana stewartia promotes procollagen production and inhibits matrix metalloproteinase-1 expression in UVB-irradiated human dermal fibroblasts. Biol Pharm Bull 2011;34:768-773.

46. Lee YR, Noh EM, Jeong EY, Yun SK, Jeong YJ, Kim JH, Kwon KB, Kim BS, Lee SH, Park CS et al. Cordycepin inhibits UVB-induced matrix metalloproteinase expression by suppressing the NF-kappaB pathway in human dermal fibroblasts. Exp Mol Med 2009;41:548-554.

47. Lee YR, Noh EM, Kwon KB, Lee YS, Chu JP, Kim EJ, Park YS, Kim BS, Kim JS. Radix clematidis extract inhibits UVB-induced MMP expression by suppressing the NF-kappaB pathway in human dermal fibroblasts. Int J Mol Med 2009;23:679-684. 